\title{
Thermal control of the temperature control furnace and the upper computer design
}

\author{
Sijia Tian \\ School of North China Electric Power University, Baoding 071000, China; \\ 792706126@qq.com
}

Keywords: temperature control, upper computer, temperature controll furnace

\begin{abstract}
Temperature is one of the most commonly used parameters in industrial and agricultural production process, master precision of temperature measurement and control technology, has an important significance for practical applications. Furnace temperature control system is mainly to complete the temperature acquisition, programming control algorithm, the control signals of the heating furnace by pulse width modulation technology, adjust the duty ratio control of electric heating furnace heating effective voltage on both ends of the wire, to adjust the temperature of the furnace temperature control. This article will take temperature controll furnace as the control object,using single-chip microcomputer in the upper computer to control furnace temperature control and display the temperature curve.
\end{abstract}

\section{Introduction}

Temperature controlling stove works under $220 \mathrm{v}$ ac voltage, internal cabin heating circuit and silicon controlled rectifier control circuit. so just need to control the specific pin of the circuit to input the duty cycle of the $P W M$ wave, can realize the control of heating and heating rate..

\section{The temperature measurement circuit design}

\subsection{Temperature measurement circuit principle}

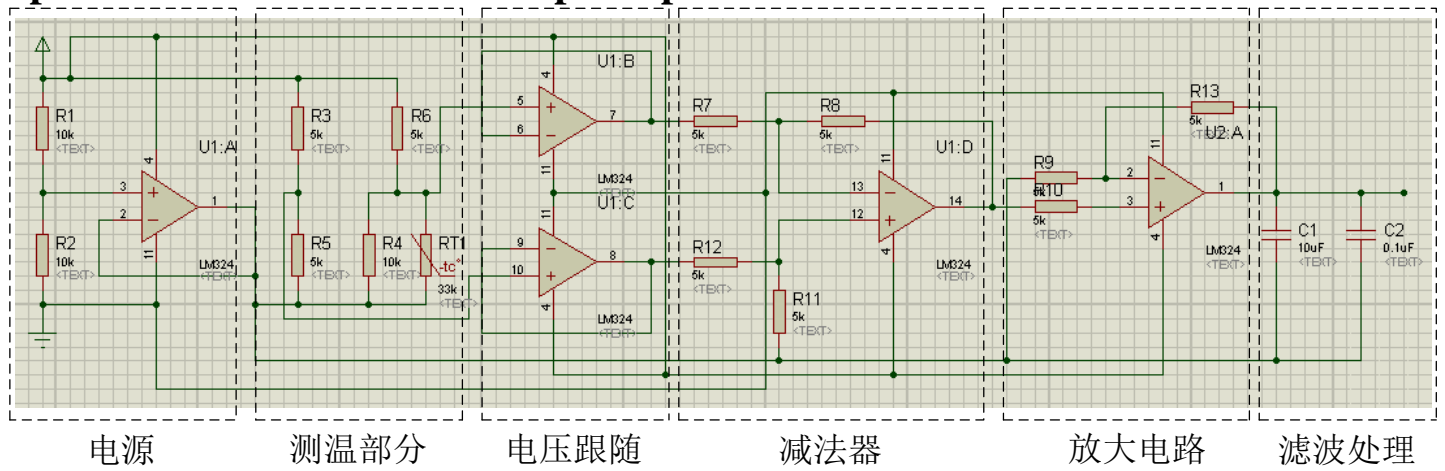

Figure 1 . temperature measurement circuit of temperature controlling stove

Above is the temperature control furnace's temperature measurement circuit diagram. Worth mentioning is this article joined the filtering processing parts in the circuit design, namely in voltage output to add two capacitors. And in the design of upper computer joined the code to remove outliers, and have achieved good filtering, smoothing the role of the temperature curve.

\subsection{Temperature characteristic curve fitting}

Temperature characteristic curves reflect the corresponding relationship between the furnace temperature and the output voltage.

A given duty cycle on temperature control furnace, after heated to a temperature limit ,let it natural cooling. Measure the heating temperature using a digital thermometer. In the cooling process, the actual temperature every certain limits, then read the same time temperature and voltage and record down, finally got 33 set of data.

Based on data processing, get fit curve of the following: 


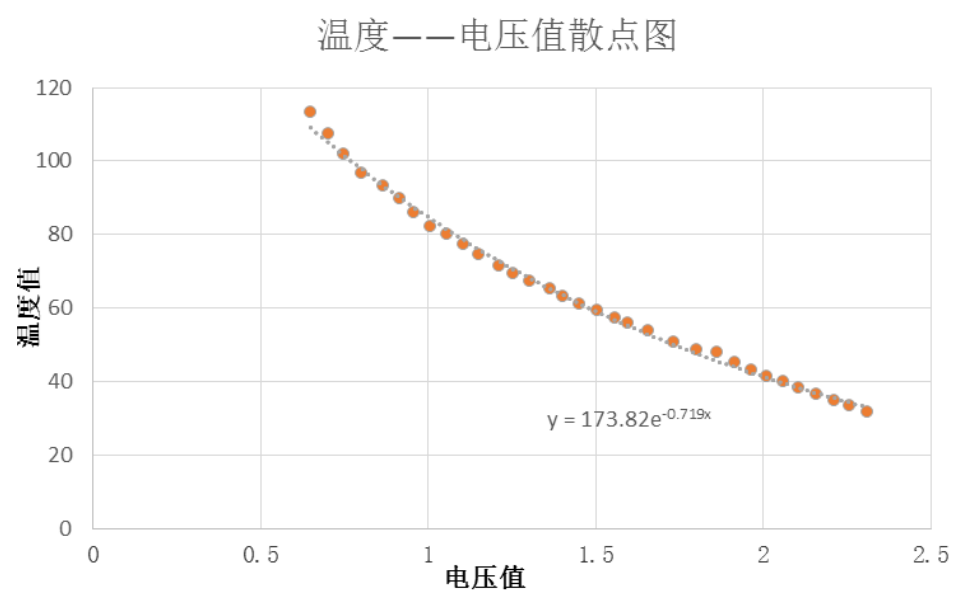

Figure 2 temperature-voltage curve fitting

Analysis of this image, see below $80^{\circ}$ temperature, the curve is almost a straight line, linearity is very good. (this is also related to the characteristics of the selected temperature measuring element) and more than $80^{\circ}$, system linearity slightly change.as far as possible in order to make the curve accurately reflect the corresponding relationship between voltage and temperature, abandoned to scatter in linear fitting and turned to synthesis a index curve.

Curve equation is:

$$
y=173.82 e^{-0.719 x}
$$

\section{The temperature measurement circuit design}

In order to realizing the real-time control and monitor the temperature control furnace and displaying the temperature control curve and the control process more intuitive comprehensive , use the Guide function of the Matlab building upper computer interface programming, upper computer interface is as follows:

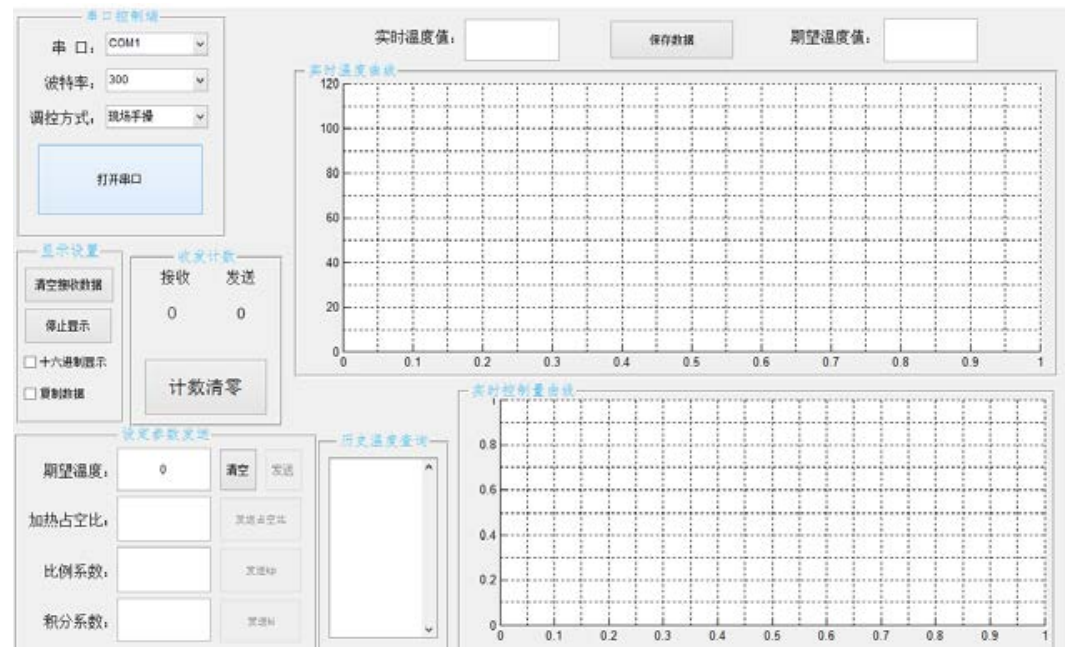

Figure 3 upper computer interface

\subsection{Main components of the upper computer}

Upper computer is mainly composed of a serial port configuration, send and receive data transceiver area, auxiliary area and curve plotting area, etc.

Serial port configuration: due to the lower computer is needed to transmit duty ratio and real-time temperature to Upper computer, so the need for a serial port communication configuration, system default 9600 serial port baud rate.

Curve drawing: curve drawing rea is composed of two pieces, one is real-time temperature drawing area, the abscissa for time, y coordinate for the temperature, the other is the drawing area of the control quantity, which drawing the duty cycle of heating. 


\subsection{Upper computer temperature control system design}

\subsection{1 “ $P W M$ automatic adjustment” project}

Heating wire in the heated at the same time with the outside world with a cooling process, and the higher the temperature of the heating wire, the faster the cooling rate, when it comes to an equal heating rate and cooling rate, the temperature of the system will remain stable and balanced.So the temperature control furnace is a self balancing system.

For such a self balancing system, add a fixed duty cycle of the wave to control the heating to make the heating rate constant. The cooling rate increased with the temperature rise. when the heating rate equals the heat dissipation, system to reach equilibrium. According to the principle acquires several groups of different duty ratio and stable temperature, drew the duty ratio-temperature curve:

占空比与最终稳定温度对应关系

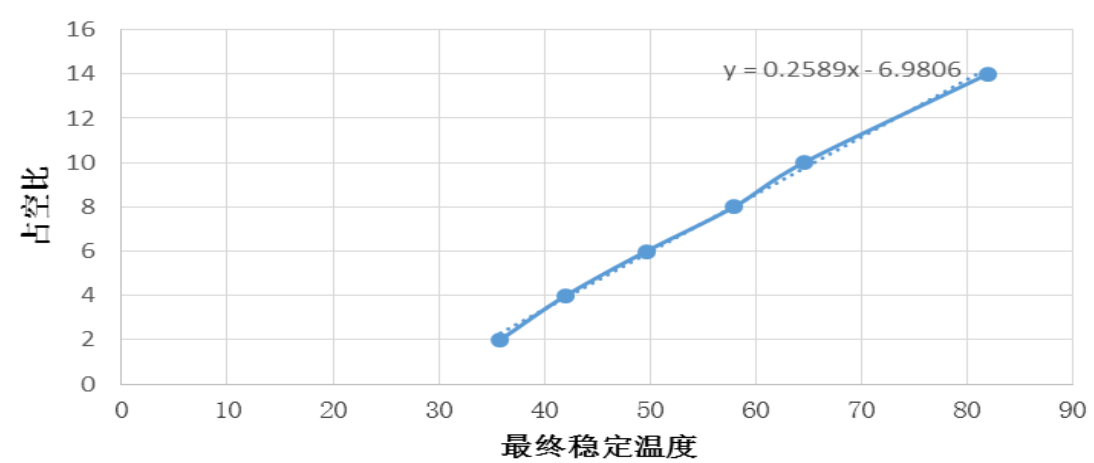

Figure 4 corresponding relations between duty ratio and stability of temperature

From the intuitive point of view, its linearity is very good. Using Excel acquired the following formula fitting:

$$
y=0.2589 x-6.9806
$$

Control thought roughly: embedding the temperature control algorithm in the upper computer program and then combining the set expectations temperature and the formula derived from the above can gain the corresponding duty ratio that makes temperature stable. Added a correction factor in order to more accurate (according to the room temperature is different under different experimental environment and random in the small scope changes). Added a correction factor $C=1.4$ in order to more accurate (according to the room temperature is different under different experimental environment and random in the small scope changes).Based on the current temperature and the $\mathrm{D}$-value between the actual temperature to a given heat duty ratio.

It is worth noting that due to the system as the slow object, temperature has a great deal of inertia. So when the real-time temperature is higher than the set temperature, can't completely stop heating, and to give a duty ratio that less than the corresponding's to the heating wire. When the curve reaches the peak overshoot, curve will drop. In the process of falling give a close duty ratio to heat. So that "for a rainy day", while the temperature higher than expected, but the heat effectively prevent the heating wire cooled down, the temperature is just right down to the expected temperature, heating wire just heating to the corresponding temperature, so that we can effectively reduce the overshoot volume curve, the curve is more stable.

\subsection{2 “ $P I$ automatic adjustment” project}

PI regulation is the method that widely used in modern engineering control. It is a kind of eliminating deviation control method based on error feedback. Before application of PI control combined with the temperature curve for system identification. The identification system is:

$$
y=\frac{20.6}{(492 \mathrm{~s}+1)}
$$

Apply controller constitute a closed-loop control system. Combining the Matlab simulation with the temperature control furnace adjustment method, when $k_{p}=1.3, k_{i}=0.02$, the control effect is ideal. 


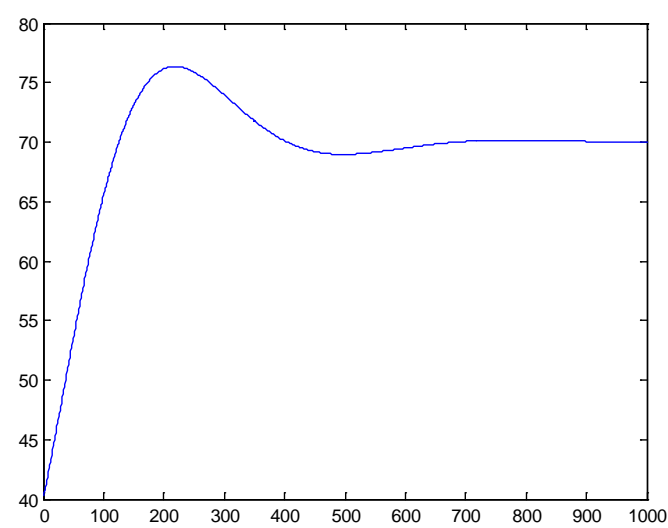

Figure 5 under the PI control temperature response curve

When the set temperature is lower than the current actual temperature , the design of the control scheme is not started. When the set temperature is lower than the current actual temperature , the design of the control scheme is not started. When the temperature is lower than expected temperature,the system begin to control. This is because of the accumulation of controlled quantity is not conducive to subsequent continue to control.

\section{Conclusion}

This article through to the temperature control of furnace temperature control system hardware design and the writing of the upper machine, using single-chip microcomputer, has realized the control of the temperature, measurement and display.

Combining of advanced temperature control method on the upper computer , improves the control precision and make control simple, suitable for widely in the field of automatic control. The temperature control is more and more important, it has great potential for growth and development value.

\section{References}

[1] Zhong-hua xie. MATLAB statistical analysis and application. Beijing University of Aeronautics and Astronautics press, 2015.

[2] Jian-hua ye. Process identification technology. Shanghai University Press,2007.5.

[3]Ke-ming xie. Principle of automatic control. Beijing: Publishing House of Electronics Industry ,2004.7

[4]Xiang-hua huang. Control system simulation. Beijing University of Aeronautics and Astronautics press, 2008.7

[5]Zi-fang liu,Zhong-xiang yang. The temperature control of the calibration device. Beijing: China Metrology Publishing House,1988.6. 